\title{
Pendampingan Pengembangan Keterampilan Guru Sekolah Dasar dalam Soal Evaluasi Pembelajaran dengan Teka-teki Silang Berbasis Smartphone
}

\author{
Usman Sutisna $^{1}$, Mia Fitriah Elkarimah*2 \\ usmansutisna09@gmail.com¹, el.karimah@gmail.com² \\ ${ }^{1,2}$ Universitas Indraprasta Jakarta
}

Received: 3 Maret 2021

Accepted: 24 Mei 2021 Online Published: 31 Juli 2021

DOI: 10.29408/ab.v2i1.3249

URL: http://dx.doi.org/10.29408/ab.v2i1.3249

\begin{abstract}
Abstrak: Era industri 4.0 mengharuskan seorang pendidik harus mampu meningkatkan kompetensi atau keahlian dalam penggunaan teknologi informasi dalam pendidikan. Pemanfaatan teknologi dalam dunia pendidikan sangat luas, diantaranya yaitu pembuatan media pembelajaran dan media evaluasi pembelajaran. Tujuan pelatihan ini adalah mengembangkan keterampilan guru Sekolah Dasar Negeri Menteng Atas 01 khususnya dalam bidang IT dan tujuan akhir dari kegiatan abdimas ini diharapkan dapat mendorong para guru untuk sama-sama bisa memanfaatkan media pembelajaran khususnya media smartphone dalam rangka pembuatan soal evaluasi pembelajaran dengan bentuk teka-teki silang online, terlebih dalam kondisi pandemi yang kegiatan belajar mengajar kini dilakukan secara daring. Mitra pengabdian adalah seluruh guru di SDN Menteng Atas. PKM dilaksanakan pada tanggal 13 April 2020 bertempat di SDN Menteng Atas 01 dihadiri 15 peserta secara online via zoom. Metode yang digunakan yaitu demonstasi dan ceramah. Hasil dari kegiatan pengabdian masyarakat adalah para guru SDN Menteng Atas 01 Setiabudi Jakarta Selatan mampu membuatan soal teka-teki silang online berbasis smartphone secara mandiri
\end{abstract}

Kata Kunci: Evaluasi Pembelajran; Smartphone; Teka-Teki Silang (TTS)

\begin{abstract}
The industrial 4.0 era requires an educator to increase competence or expertise in the use of information technology in education. The use of technology in education is extensive, including learning media and learning evaluation media. This goal is to develop the skills of SD Menteng Atas 01 teachers, especially in the IT field, and the ultimate goal of this community service activity is to encourage teachers to share learning media, especially smartphone media, in order to make learning evaluations. In the form of online crossword puzzles, especially during the pandemic, teaching and learning activities are now being carried out boldly. The service partners are all teachers at Menteng Atas Elementary School. Community service was held on April 13, 2020, at SDN Menteng Atas 01, followed by 15 participants online via zoom. The method used is demonstration and lecture. As a result of this community service activity, the teachers of SDN Menteng Atas 01 Setiabudi, South Jakarta, were able to create online crossword puzzles independently with a smartphone.
\end{abstract}

Keyword: Crossword Puzzle; Learning Evaluation; Smartphone 
Sutisna, U., \& Elkarimah, M. F. (2021). Pendampingan pengembangan keterampilan guru sekolah dasar dalam soal evaluasi pembelajaran dengan teka-teki silang berbasis smartphone. ABSYARA: Jurnal Pengabdian Pada Masyarakat, 2(1), 15-25. doi:10.29408/ab.v2i1.3249

\section{PENDAHULUAN}

Pelaksanaan kurikulum 2013 sudah dilaksanakan hampir sudah menyeluruh di satuan pendidikan dan diharapkan pada tahun 2019 seluruh sekolah sudah dapat menggunakan kurikulum 2013 ini secara nasional. Pembekalan mengenai implementasi kurikulum 2013 untuk guru dan kepala sekolah dilakukan melalui pendidikan dan pelatihan, walaupun pelaksanaannya belum semuanya menggunakan akan tetapi bertahap. Ditahun ajaran baru semester dua tahun ajaran 2019/2020 semua sekolah wajib menggunakan kurikulum 2013 (Kurtilas). Kurikulum 2013 memiliki keistimewaan dengan penerapan sistem pembelajaran tematik-integratif dengan pendekatan saintifik diseluruh jenjang kelas, hal inilah yang membedakan kurikulum ini dengan kurikulum sebelumnya (penerapan tematik hanya di kelas $1-3$, sedangkan untuk kelas $4-6$ berbasis mata pelajaran). Pada kurikulum ini menggunakan penilaian autentik, yaitu penilaian yang menampilkan situasi real dengan pendemonstrasian penerapan pengetahuan dan keterampilan esensial yang bermakna dengan menggunakan kriteria holistik (sikap, keterampilan, pengetahuan) dan berbagaimacam cara, yang mencakup penilaian produk, sikap dan proses. Banyak guru yang masih bingung dan meraba dalam kurikulum ini sehingga diperlukan media pembelajaran agar mudah dipahami (Sutisna \& Elkarimah, 2020). Penggunaan teknologi informasi pada kurikulum 2013 sangat anjurkan, karena teknologi informasi sangat mendukung proses pembelajaran dalam kurikulum 2013 (Abadi, dkk., 2018).

Dalam setiap kurikulum pendidikan memiliki proses evaluasi pembelajaran yang digunakan sebagai salah satu tolak ukur untuk mengetahui tingkat keberhasil suatu model pembelajaran yang digunakan. Pada proses ini, guru atau pendidik dapat menggunakan beberapa teknik evaluasi, salah satunya dengan menggunakan soal-soal pembelajaran untuk tugas harian atau untuk ujian semester. Dalam pembuatan soal-soal ini dapat dilakukan dengan menggunakan bantuan teknologi, apalagi mengingat situasi pandemi Covid-19 saat ini yang memberikan dampat besar pada dunia pendidikan di Indonesia (Sutisna, dkk., 2020). Penggunaan teknologi dalam pembuatan soal-soal akan meminimalisir kecurangan peserta didik karena penerapan sistem satu akun untuk satu pengguna (Dewi, dkk., 2020).

Pada dasarnya mitra tidak memiliki permasalahan yang dinilai perlu diselesaikan, hanya saja ketika era digital yang mengharuskan para guru untuk menyesuaikan pendekatan pembelajaran secara daring. Dengan alasan inilah tim abdimas UNINDRA mengadakan pelatihan dengan tema "Pengembangan Keterampilan Guru Sekolah Dasar Dalam Soal Evaluasi Pembelajaran Dengan Teka-teki Silang Berbasis Smartphone”. Evalusi dengan penggunaan kertas ujian tidak melulu menjadi rujukan, baik ujian pekan harian, PTS, dan PAT. Selain lebih mudah dan praktis dalam koreksi, pendekatan ini juga dinilai menjadi chalenge dan lebih menarik bagi para peserta didik. Tim menyiapkan segala perangkat yang akan digunakan dalam pelatihan sekaligus berkoordinasi dengan mitra apa saja yang harus ada dan dilakukan selama pelatihan seperti konektivitas internet, smartphone, infokus dan lain sebagainya. 
Sutisna, U., \& Elkarimah, M. F. (2021). Pendampingan pengembangan keterampilan guru sekolah dasar dalam soal evaluasi pembelajaran dengan teka-teki silang berbasis smartphone. ABSYARA: Jurnal Pengabdian Pada Masyarakat, 2(1), 15-25. doi:10.29408/ab.v2i1.3249

\section{METODE PELAKSANAAN}

\section{Waktu dan Lokasi}

Pengabdian pada masyarakat ini dilaksanakan dari tanggal 13 April - 16 Juni 2020. Tempat pelaksanaan abdimasa SDN Menteng Atas 01, Setiabudi, Kota Jakarta Selatan, Daerah Khusus Ibukota Jakarta.

\section{Prosedur pelaksanaan}

Kegiatan ini menerapkan metode daring dengan praktik langsung (demonstrasi) dan ceramah. Metode ini digunakan karena dalam pelatihan lebih mudah dipahami oleh peserta pelatihan (Arianti, dkk., 2020).

Adapun tahap-tahap pelaksanaan kegiatan adalah sebagai berikut:

1. Persiapan

Pada tahap persiapan, dimulai dari sosialisasi program dan pembentukan tim pelaksana kegiatan. Setelah itu dilakukan koordinasi dengan pihak sekolah dan mengurus perizinan kegiatan. SDN Menteng Atas 01. Setelah itu menyusun proposal kegiatan. Tim Pengabdian masyarakat diberikan pendampingan sesuai dengan tema yang sudah di ijinkan.

2. Pelaksanaan

Tahap pelaksanaan ini merupakan tahap yang membutuhkan konsistensi didalam pengabdian masyarakat diantaranya :

a) Pelatihan

Dalam tahap pelatihan ini guru-guru ikut dalam pelaksanaan kegiatan pengabdian masyarakat. Pelatihan dilaksanakan secara daring. Hal ini dikarenakan pelatihan secara daring paling cocok dengan keadaan pandemi Covid-19 saat ini (Samsuri, dkk., 2020).

b) Instrumentasi

Tahap ini guru diharapkan sudah mahir mengoperasikan smartphone.

3. Evaluasi

Tahapan yang terakhir adalah tahap evaluasi. Evaluasi dilakukan untuk mengukur tingkat keberhasilan dari suatu kegiatan yang telah dilakukan. Hasil evaluasi dapat dijadikan masukan pada kegiatan selanjutnya. Dalam hal ini, evaluasi dilakukan dengan cara guru guru membuat soal-soal dengan teka-teki silang (TTS) berbasis smartphone.

\section{HASIL DAN PEMBAHASAN}

\section{HASIL}

Dari hasil pelaksanaan kegiatan pengabdian pada masyarakat di SDN Menteng Atas 01 didapatkan hasil seperti terlihat pada tabel 1. Berikut ini:

Tabel 1. Hasil kegiatan pengabdian pada masyarakat

\begin{tabular}{|c|c|c|c|c|}
\hline No. & Hari/Tanggal & Kegiatan & Peserta & Hasil \\
\hline 1 & April 2020 & $\begin{array}{l}\text { - Observasi awal ke } \\
\text { Guru bidang studi } \\
\text { dan wali kelas. }\end{array}$ & Tim Dosen & $\begin{array}{l}\text { - Ditemukan } \\
\text { sebagian besar } \\
\text { guru belum }\end{array}$ \\
\hline
\end{tabular}


Sutisna, U., \& Elkarimah, M. F. (2021). Pendampingan pengembangan keterampilan guru sekolah dasar dalam soal evaluasi pembelajaran dengan teka-teki silang berbasis smartphone. ABSYARA: Jurnal Pengabdian Pada Masyarakat, 2(1), 15-25. doi:10.29408/ab.v2i1.3249

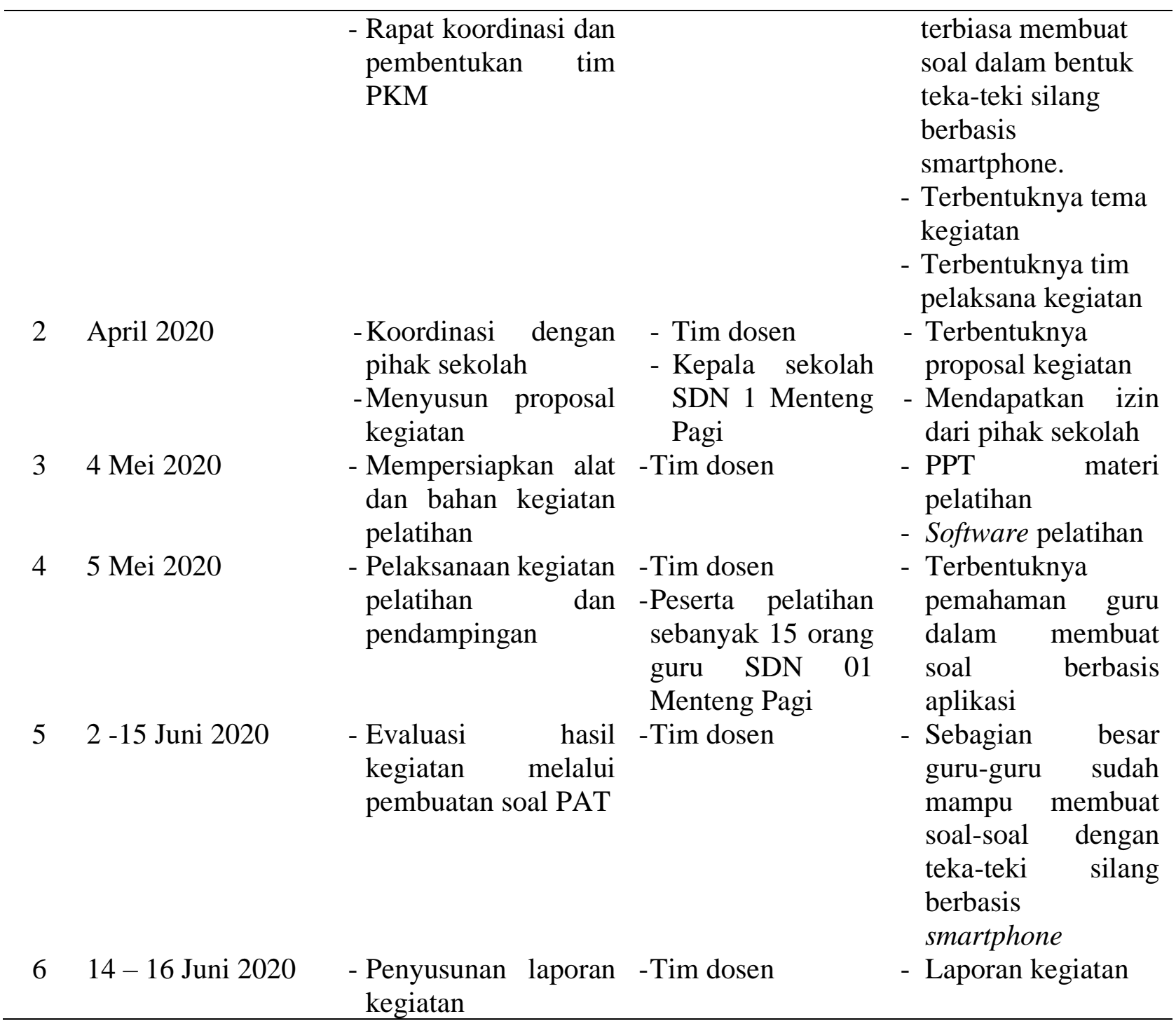

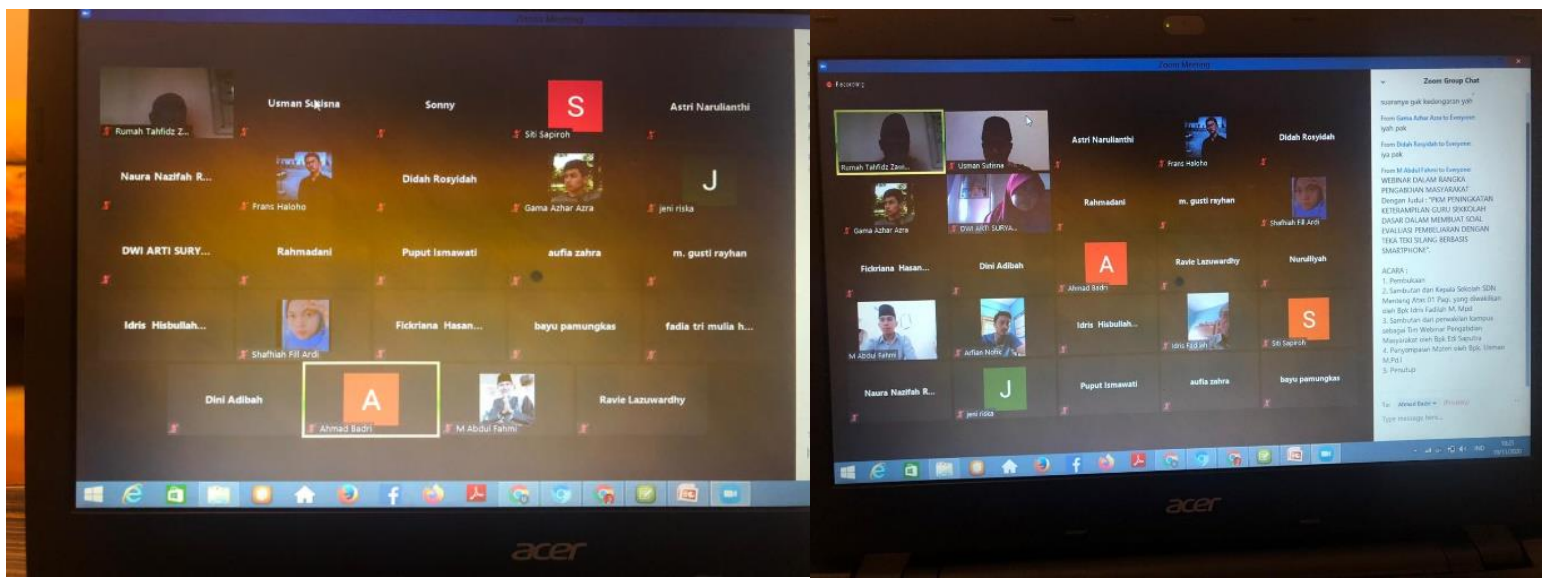

Gambar 1. Peserta pelatihan pembuatan soal teka-teki silang berbasis smartphone

Adapun langkah-langkah pembuatan soal teka-teksi silang dapat dilihat pada gambar berikut ini: 
Sutisna, U., \& Elkarimah, M. F. (2021). Pendampingan pengembangan keterampilan guru sekolah dasar dalam soal evaluasi pembelajaran dengan teka-teki silang berbasis smartphone. ABSYARA: Jurnal Pengabdian Pada Masyarakat, 2(1), 15-25. doi:10.29408/ab.v2i1.3249

Sebelum melakukan langkah-langkah membuat TTS online ini, siapkan terlebih dahulu soal (pertanyaan) berikut dengan jawabannya di Microsoft Word. Kemudian lakukan langkahlangkah berikut ini.

\section{Langkah 1}

Buka browser, misalnya Google Chrome, kemudian ketik www.xwords-generator.de

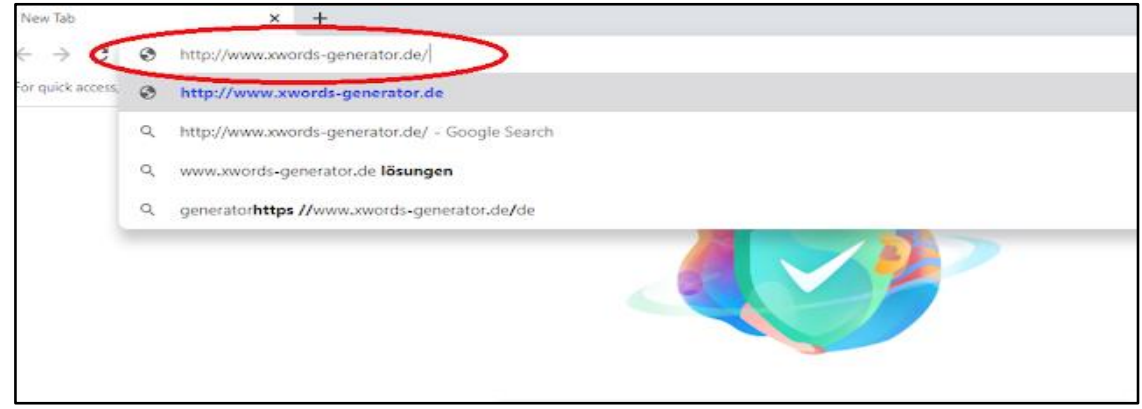

Gambar 2. Membuka alamat situs aplikasi teka-teki silang

\section{Langkah 2}

Klik tombol EN di pojok kanan atas untuk mengubah bahasa menjadi bahasa Inggris untuk lebih memudahkan kita memahami perintah-perintahnya (bahasa default adalah bahasa Jerman).

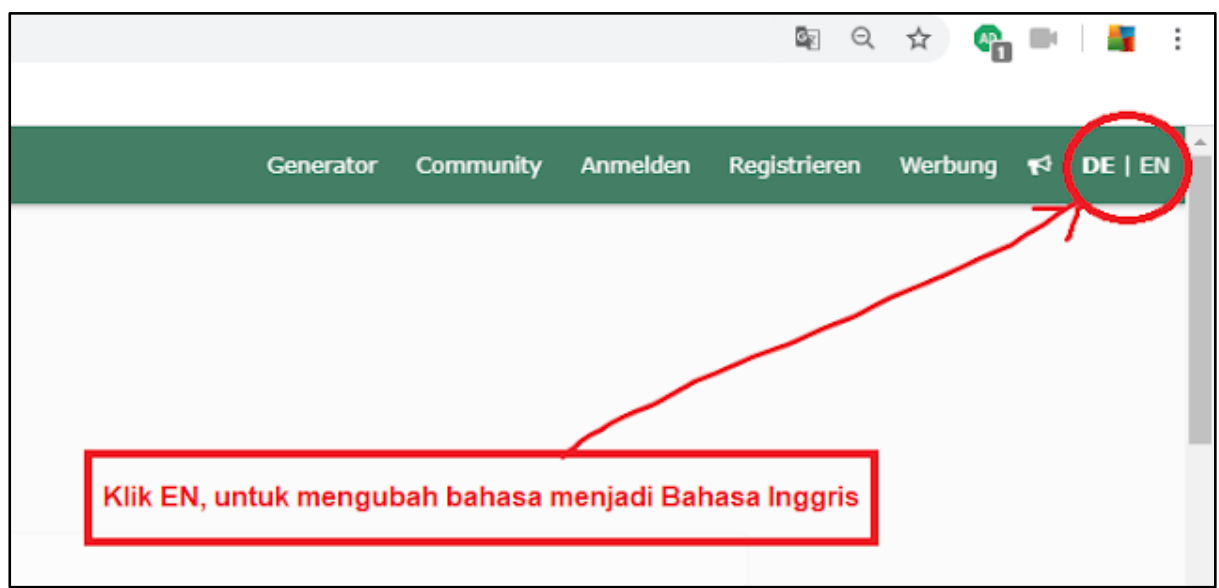

Gambar 3. Pemilihan bahasa dalam aplikasi

\section{Langkah 3}

Klik "Sign up" untuk mendaftar. Isi semua kolom data yang dibutuhkan, seperti alamat email, nama dan password. 
Sutisna, U., \& Elkarimah, M. F. (2021). Pendampingan pengembangan keterampilan guru sekolah dasar dalam soal evaluasi pembelajaran dengan teka-teki silang berbasis smartphone. ABSYARA: Jurnal Pengabdian Pada Masyarakat, 2(1), 15-25. doi:10.29408/ab.v2i1.3249

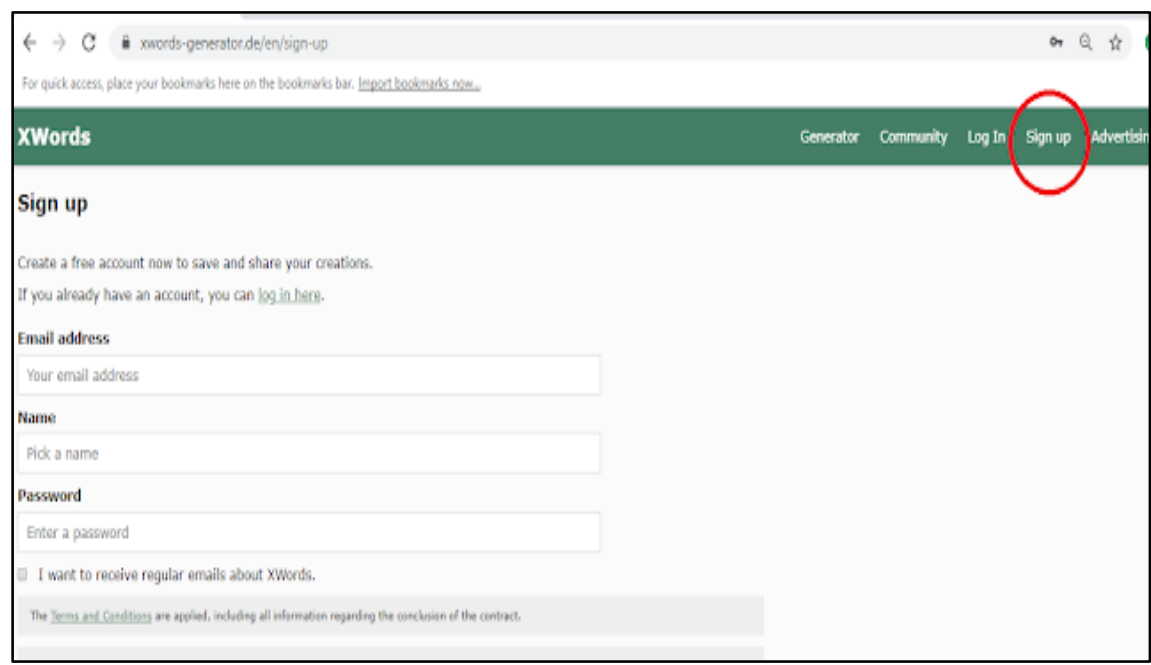

\section{Langkah 4}

Gambar 4. Cara untuk mendaftar pada aplikasi

Setelah terdaftar, klik "Log in" untuk masuk ke halaman utama.

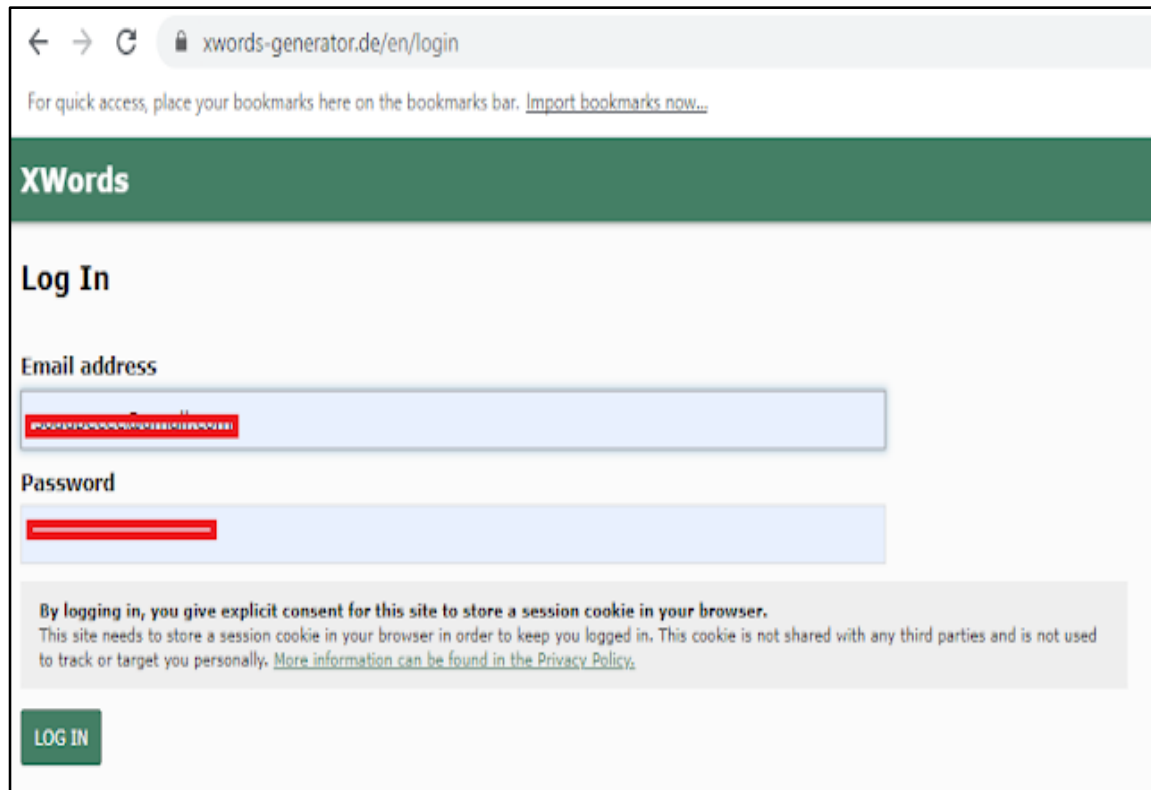

Gambar 5. Halaman login pengguna

\section{Langkah 5}

Isi kolom "Questions 1" dengan pertanyaan nomor 1, isi kolom "Answer1" dengan jawaban soal nomor 1 yang sebelumnya sudah siapkan di Microsoft Word, tinggal copy paste saja. 
Sutisna, U., \& Elkarimah, M. F. (2021). Pendampingan pengembangan keterampilan guru sekolah dasar dalam soal evaluasi pembelajaran dengan teka-teki silang berbasis smartphone. ABSYARA: Jurnal Pengabdian Pada Masyarakat, 2(1), 15-25. doi:10.29408/ab.v2i1.3249

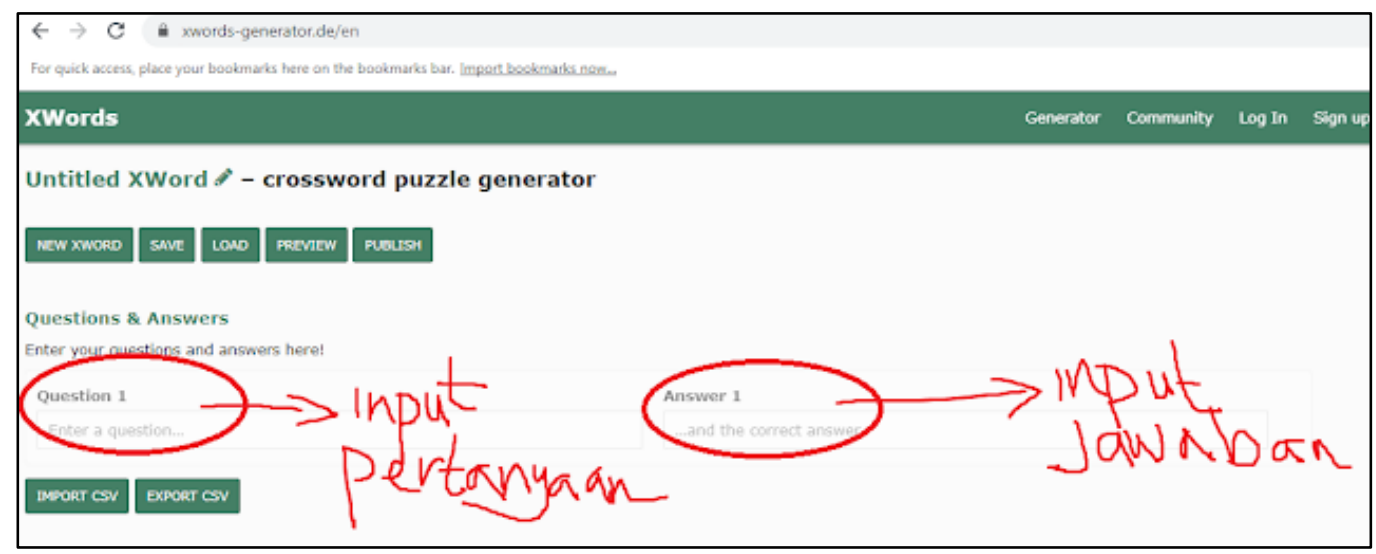

\section{Langkah 6}

Gambar 6. Membuat pertanyaan

Isi kolom-kolom pertanyaan dan jawaban tesebut sampai dengan pertanyaan dan jawaban terakhir

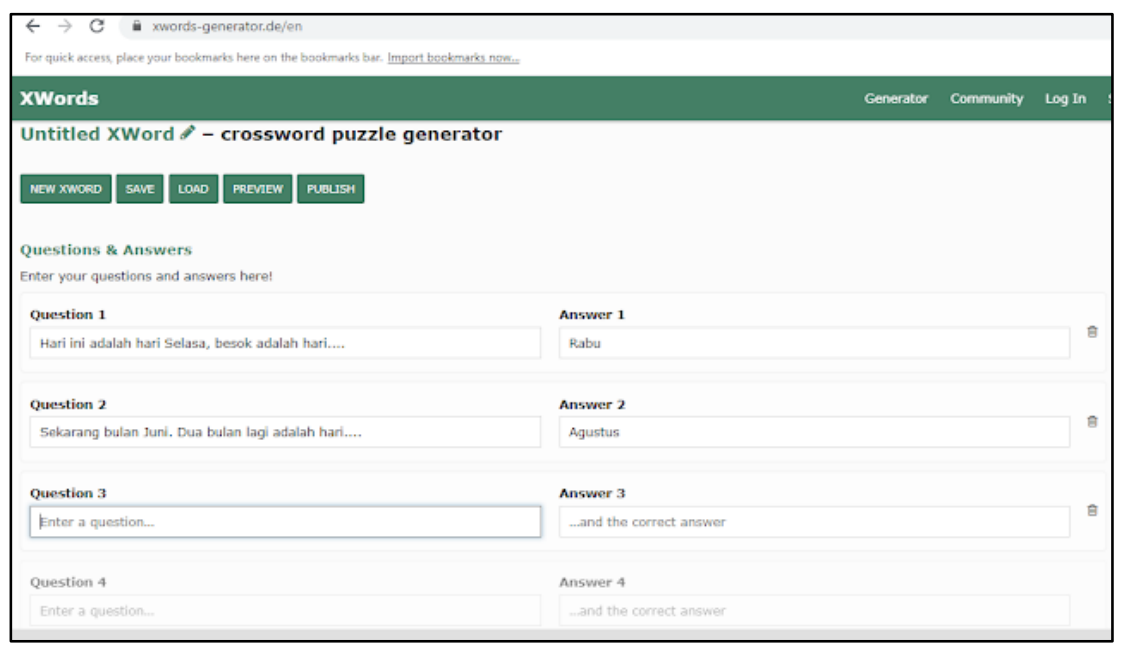

Gambar 7. Membuat pertanyaan dan jawaban

\section{Langkah 7}

Setelah semua pertanyaan dan jawaban diisi, klik "Save" untuk menyimpan hasil input pertanyaan dan jawaban.

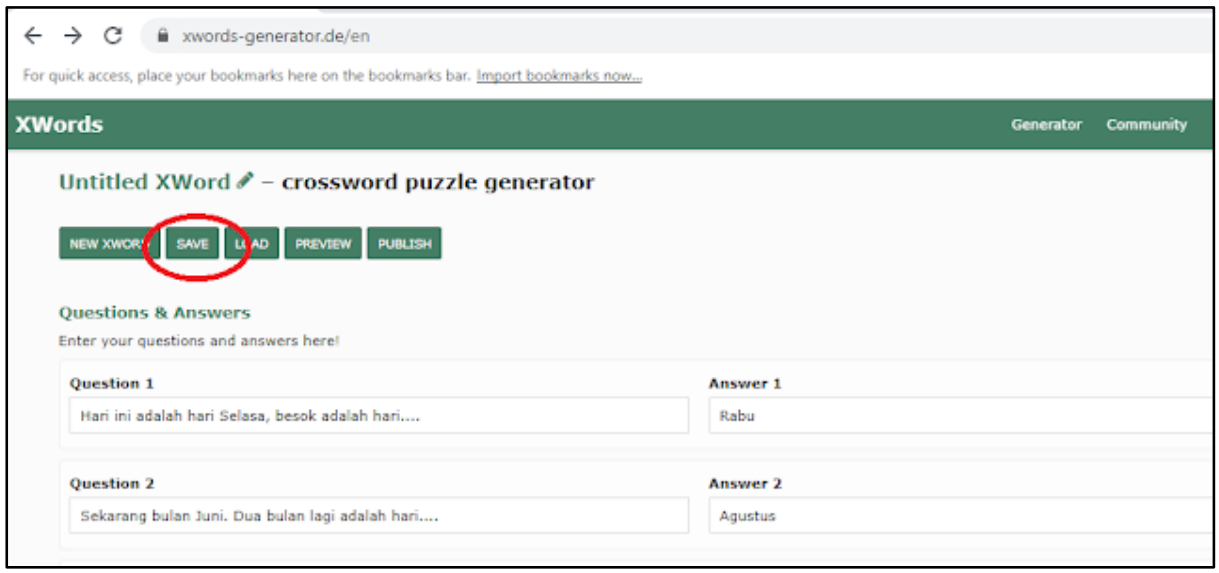

Gambar 8. Menyimpan pertanyaan yang telah dibuat 
Sutisna, U., \& Elkarimah, M. F. (2021). Pendampingan pengembangan keterampilan guru sekolah dasar dalam soal evaluasi pembelajaran dengan teka-teki silang berbasis smartphone. ABSYARA: Jurnal Pengabdian Pada Masyarakat, 2(1), 15-25. doi:10.29408/ab.v2i1.3249

\section{Langkah 8}

Setelah klik "Save", kemudian klik "Generate Puzzle"

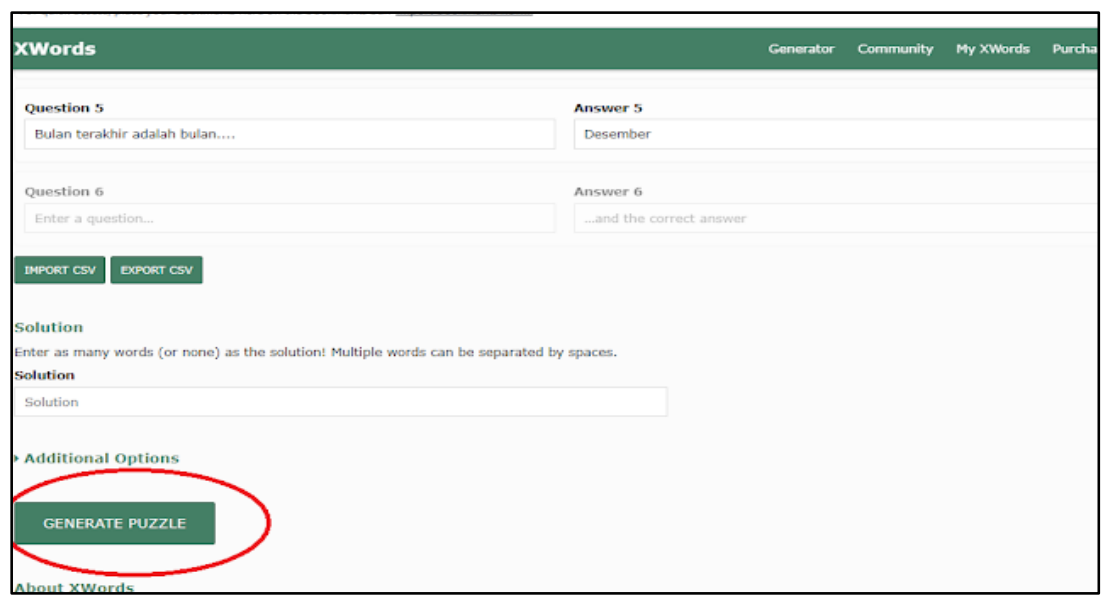

Gambar 9. Generate puzzle

\section{Langkah 9}

Kemudian klik "Publish"

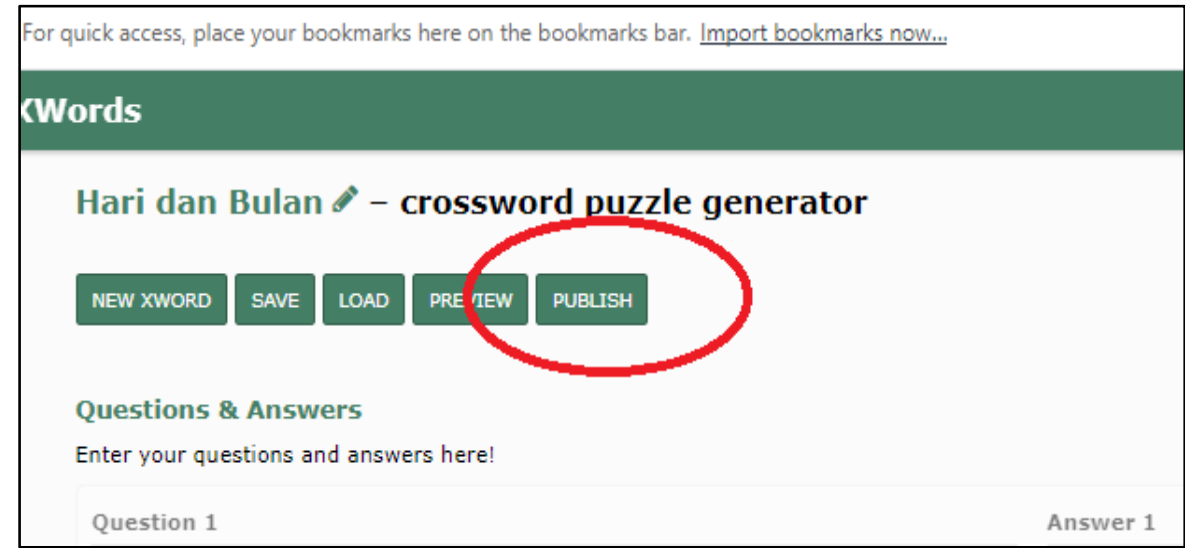

Gambar 10. Mempublish pertanyaan yang sudah dibuat

\section{Langkah 10}

Masukkan/tulis judul pada kolom "Change Title", kemudian klik "Save Changes"

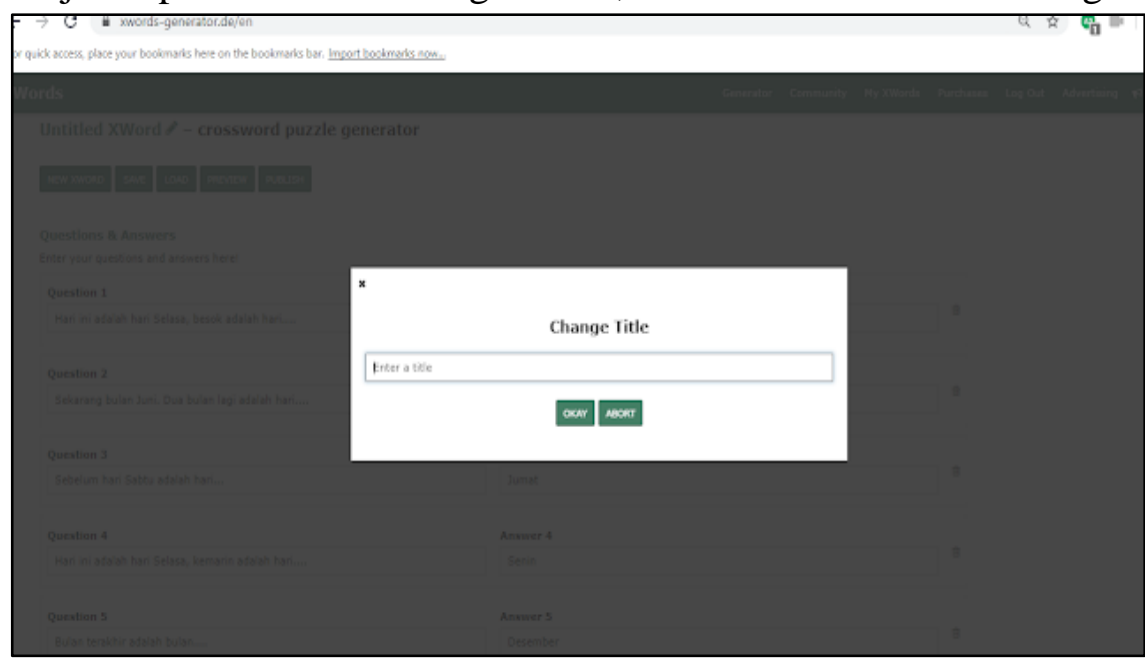

Gambar 11. Mengubah judul teka-teki silang 
Sutisna, U., \& Elkarimah, M. F. (2021). Pendampingan pengembangan keterampilan guru sekolah dasar dalam soal evaluasi pembelajaran dengan teka-teki silang berbasis smartphone. ABSYARA: Jurnal Pengabdian Pada Masyarakat, 2(1), 15-25. doi:10.29408/ab.v2i1.3249

\section{Langkah 11}

Klik "Publish XWords"

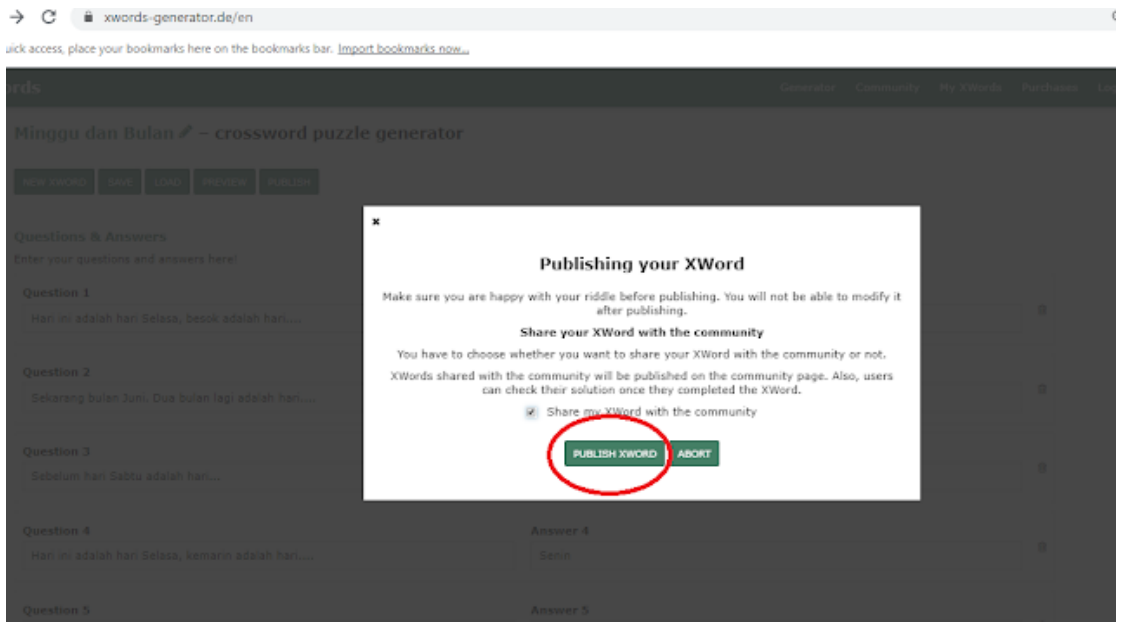

\section{Langkah 12}

Gambar 12. Mempublish XWords

Klik "Embed", lalu salin/copy script, lalu klik OK

C in xwords-generatorde/envimords

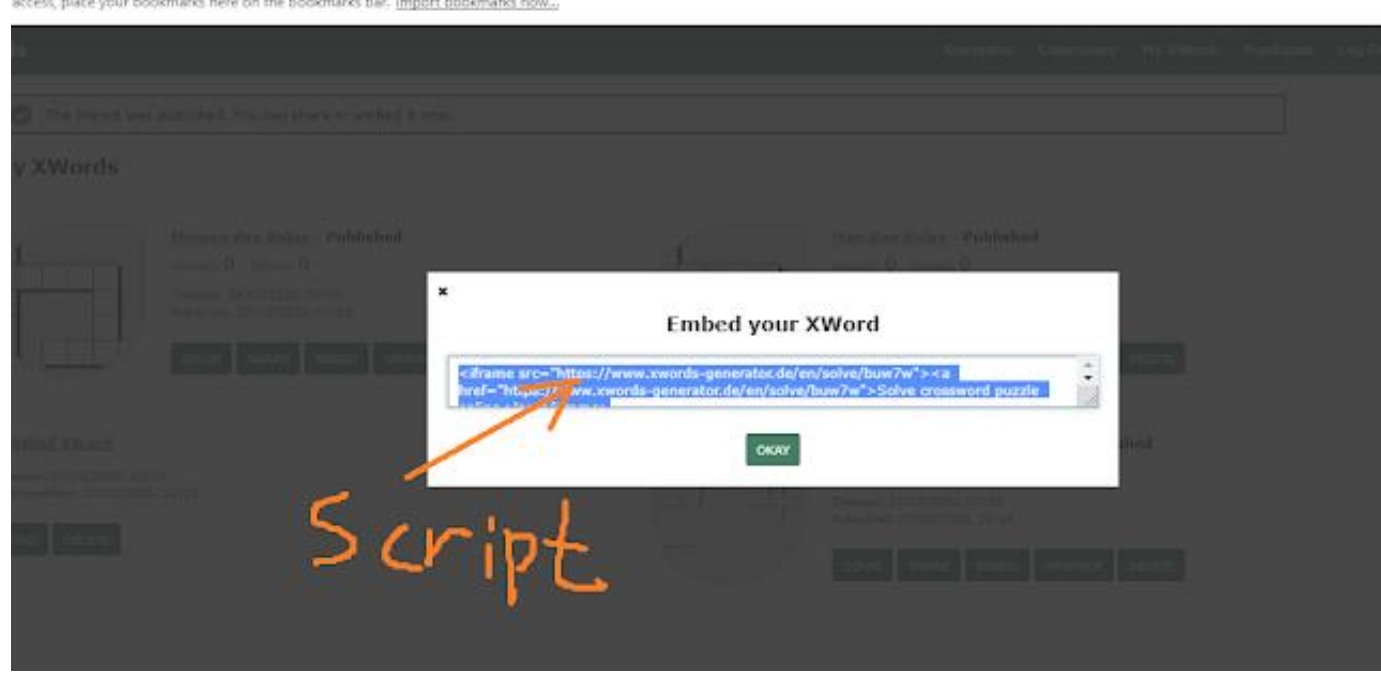

Gambar 13. Membuat link teka teki silang

\section{PEMBAHASAN}

Meningkatkan kemampuan profesional khususnya dalam bidang IT, mendorong para guru untuk lebih memanfaatkan media pembelajaran khususnya media smartphone dalam menunjang tujuan pembelajaran pada kurikulum 2013 di masa pandemi. Kegiatan pengabdian masyarakat terasa sangat berbeda ketika dilakukan di masa pandemi covid-19, dimana seluruh tahapan pelaksanaan hampir dilaksanakan secara online. Pada tahap pelaksanaan, narasumber langsung memaparkan informasi-informasi penting serta langkah-langkah yang dapat dilakukan oleh para peserta abdimas dalam rangka pembuatan soal evaluasi pembelajaran dengan teka-teki silang online melalui smartphone. Sebelumnya tim langsung meminta agar seluruh peserta untuk secara langsung mengikuti dan menggunakan handphonenya masing- 
Sutisna, U., \& Elkarimah, M. F. (2021). Pendampingan pengembangan keterampilan guru sekolah dasar dalam soal evaluasi pembelajaran dengan teka-teki silang berbasis smartphone. ABSYARA: Jurnal Pengabdian Pada Masyarakat, 2(1), 15-25. doi:10.29408/ab.v2i1.3249

masing agar secara teknis bapak ibu guru langsung bisa membuat soal teka-teki silang online berbasis smartphone.

Setelah pemaparan, tim dosen juga menjelaskan bahwa hasil pekerjaan siswa tidak dapat diimport seperti soal-soal pilihan ganda yang ada pada google form, pekerjaan siswa masih dilaporkan secara manual dengan cara screenshoot dan dikirim ke guru nya melalui ponsel masing-masing siswa. Kelebihan dan kekurangan dijelaskam oleh narasumber, namun minimal ada salah satu cara yang bisa digunakan oleh para guru dalam memberikan soal evaluasi yang dipandang sebagai cara baru dalam mengevaluasi tujuan pembelajaran. Tekateki silang (TTS) berbasis smartphone ini, dapat menampilkan nilai siswa secara langsung, sehingga dapat meminimalisir kecurangan peserta didik karena aplikasi ini menerapkan satu akun satu peserta.

Dari hasi evaluasi menunjukkan bahwa sebagian besar guru-guru sudah mampu membuat soal-soal dengan teka-teki silang (TTS) berbasis smartphone. Hal ini sejalan dengan hasil penelitian Muhatarom (2016) dalam pembelajaran matematika di kelas VII dan hasil penelitian Khailullah (2012) yang menggunakan TTS berbasis smartphone pada pelajaran bahasa arab.

\section{SIMPULAN}

Hasil dari kegiatan pengabdian masyarakat adalah para guru SDN Menteng Atas 01 Setiabudi Jakarta Selatan mampu memperoleh pengetahuan tentang pembuatan soal teka-teki silang online berbasis smartphone secara mandiri. Sehingga para guru diharapkan ke depan mampu memberikan terobosan-terobosan baru dalam mendesai baik proses maupun evaluasi pembelajaran yang lebih fresh dan bervariatif, sehingga apa yang menjadi tujuan pendidikan dapat tercapai secara maksimal. Guru diharapakan dapat meluangkan waktu untuk terus menggali informasi tentang desain-desain evaluasi pembelajaran terkini yang dapat di akses via internet. Guru terus menerus meningkatkan profesionalitasnya dengan mengembangkan pengetahuan dalam membuat media pembelajaran yang lebih baik.

\section{PERNYATAAN PENULIS}

Artikel pengabdian kepada masyarakat berjudul "Pendampingan Pengembangan Keterampilan Guru Sekolah Dasar dalam Soal Evaluasi Pembelajaran dengan Teka-teki Silang Berbasis Smartphon" ini belum pernah dipublikasikan dalam jurnal ilmiah manapun.

\section{DAFTAR PUSTAKA}

Abadi, J., Arianti, B. D. D., \& Wirasasmita, R. H. (2018). Pengembangan media lembar kerja siswa (LKS) berbasis web pada mata pelajaran jaringan dasar. Edumatic: Jurnal Pendidikan Informatika, 2(1), 42-51.

Arianti, B. D. D., Kholisho, Y. N., Ismatulloh, K., Wirasasmita, R. H., Uska, M. Z., Fathoni, A., \& Jamaluddin, J. (2020). Pelatihan Computer Based Test (CBT) Ujian Nasional 
Sutisna, U., \& Elkarimah, M. F. (2021). Pendampingan pengembangan keterampilan guru sekolah dasar dalam soal evaluasi pembelajaran dengan teka-teki silang berbasis smartphone. ABSYARA: Jurnal Pengabdian Pada Masyarakat, 2(1), 15-25. doi:10.29408/ab.v2i1.3249

Untuk Siswa SMK di Lombok Timur. ABSYARA: Jurnal Pengabdian Pada Masyarakat, 1(1), 22-32.

Arifin, Z., (2009). Konsep dan Model Pengembangan Kurikulum. Bandung: Remaja Rosdakarya.

Dewi, R. M., Ghofur, M. A., \& Soejoto, A. (2020). Pelatihan game edukasi Android berbasis HOTS sebagai media evaluasi pembelajaran. Abimanyu: Journal of Community Engagement, 1(1), 59-67.

Khalilullah, M. (2012). Permainan teka-teki silang sebagai media dalam pembelajaran Bahasa Arab (Mufradat). An-Nida', 37(1), 15-26.

Muhtarom, M., Nizaruddin, N., \& Sugiyanti, S. (2016). Pengembangan permainan teka-teki silang dalam pembelajaran matematika di kelas vii SMP. PYTHAGORAS: Journal of the Mathematics Education Study Program, 5(1).

Mulyasa, (2013). Konsep Kurikulum 2013. Jakarta: Buana Cipta.

Samsuri, T., Muliadi, A., Muhali, M., Asy'ari, M., Prayogi, S., \& Hunaepi, H. (2020). Pelatihan desain media interaktif pada pembelajaran daring bagi dosen pendidikan biologi. ABSYARA: Jurnal Pengabdian Pada Masyarakat, 1(2), 64-69.

Sutisna, U., \& Elkarimah, M. F. (2020). Peningkatan keterampilan guru sekolah dasar dalam penayangan video pada Microsoft Powerpoint dengan teknik hyperlink. Rangkiang: Jurnal Pengabdian Pada Masyarakat, 2(1), 28-31.

Sutisna, U., Elkarimah, M. F., \& Asma, F. R. (2020). Pengembangan kompetensi profesional guru PAI melalui pemanfaatan teknologi informasi. ABSYARA: Jurnal Pengabdian Pada Masyarakat, 1(2), 43-48. 